\title{
Cortical inhibition and habituation to evoked potentials: relevance for pathophysiology of migraine
}

\author{
Filippo Brighina · Antonio Palermo • \\ Brigida Fierro
}

Received: 20 September 2008/Accepted: 31 December 2008/Published online: 10 February 2009

(C) Springer-Verlag 2009

\begin{abstract}
Dysfunction of neuronal cortical excitability has been supposed to play an important role in etiopathogenesis of migraine. Neurophysiological techniques like evoked potentials (EP) and in the last years non-invasive brain stimulation techniques like transcranial magnetic stimulation (TMS) and transcranial direct current stimulation gave important contribution to understanding of such issue highlighting possible mechanisms of cortical dysfunctions in migraine. EP studies showed impaired habituation to repeated sensorial stimulation and this abnormality was confirmed across all sensorial modalities, making defective habituation a neurophysiological hallmark of the disease. TMS was employed to test more directly cortical excitability in visual cortex and then also in motor cortex. Contradictory results have been reported pointing towards hyperexcitability or on the contrary to reduced preactivation of sensory cortex in migraine. Other experimental evidence speaks in favour of impairment of inhibitory circuits and analogies have been proposed between migraine and conditions of sensory deafferentation in which down-regulation of GABA circuits is considered the more relevant pathophysiological mechanism. Whatever the mechanism involved, it has been found that repeated sessions of high-frequency rTMS trains that have been shown to up-regulate inhibitory circuits could persistently normalize habituation in migraine. This could give interesting insight into pathophysiology establishing a link between cortical inhibition and habituation and opening also new treatment strategies in migraine.
\end{abstract}

F. Brighina $(\square) \cdot$ A. Palermo $\cdot$ B. Fierro

Dipartimento di Neuroscienze Cliniche,

University of Palermo, Via G. la Loggia, 1,

90129 Palermo, Italy

e-mail: fbrighina@unipa.it
Keywords Cortical inhibition · Habituation - Migraine · Evoked potentials $\cdot$ TMS $\cdot$ rTMS $\cdot$ tDCS

\section{Introduction}

The nature and mechanisms of the brain dysfunction underlying pathophysiology of migraine are yet incompletely understood, but abnormalities of neuronal cortical excitability are believed to play an important role [1]. More in particular it has been suggested that changes in cortical activation can underlie the cortical spreading depression (CSD), a phenomenon considered the pathophysiological basis of migraine aura [2-4]. Evidence in experimental models that CSD can activate trigemino-vascular system that is considered the substrate of migraine pain, establishes then a pathophysiological link between aura and migraine [5].

Neurophysiological techniques gave important contribution to understanding of such issue highlighting possible mechanisms of cortical dysfunctions in migraine [6]. Evoked potentials (EP) and in the past years transcranial magnetic stimulation (TMS) and transcranial direct current stimulation (tDCS) allowed evaluation of cortical activation and responsiveness in migraine patients, testing pathophysiological hypotheses and opening also interesting therapeutic perspectives [7].

The most relevant EP studies evidenced that migraine patients present impairment of habituation to repeated sensorial stimulation. This abnormality was confirmed in several studies and across all sensorial modalities, making defective habituation a neurophysiological hallmark of the disease [8].

Transcranial magnetic stimulation was employed to test more directly cortical excitability in visual cortex and then 
also in motor cortex. The findings of these studies gave no univocal response, the characterization of cortical dysfunction in migraine still remaining an unsolved issue. Indeed, contradictory results have been reported pointing towards hyper- or hypo-excitability of migraine cortex [911]. In some other papers, impairment of inhibitory circuits has been shown and analogies have been proposed between migraine and conditions of sensory deafferentation in which down-regulation of GABA circuits is considered the more relevant pathophysiological mechanism [12-14].

Here we shortly discuss this evidence proposing also a working hypothesis linking impaired habituation to reduced efficiency of inhibitory circuits in migraine.

\section{Evidence of impaired habituation in migraine}

Habituation represents the simplest form of implicit learning allowing an organism to learn the features of a new stimulus. When a new stimulus is presented, if it is irrelevant or not noxious, after a succession of exposure, the animal ignores it. Habituation can be studied in humans through evoked potential stimulation. Habituation of evoked potentials is expressed by reduced amplitude of the evoked response to repeated stimulation and is observed in normal subjects while is consistently reported to be impaired in migraine. Schoenen et al. (1995) [15] first reported that migraine patients show lack of amplitude habituation to the ongoing visual evoked potential stimulation. Impaired habituation in migraine is not confined to visual inputs, but extends to all sensory modalities. Defective habituation has been indeed described in studies of auditory potentials or somato-sensory EP and also for cognitive potentials [8]. More recently impaired habituation has been found also in nociceptive sensory inputs by the technique of laser evoked potentials [16]. Moreover, impaired habituation in migraine has been shown to affect also reflex activities like Blink reflex, induced either by somatosensorial or nociceptive stimulation [17-20].

Schoenen et al. (1996) [21], invoking the theory of the "ceiling" of neural activation, explained the lack of habituation in migraine as following a reduced pre-activation level of sensory cortex. According to this theory, healthy subjects that have normal pre-activation of sensory cortex easily reach the top ("ceiling") of response activity after repeated sensory stimulation and show habituation. Differently, migraineurs, starting by a lower level of activation have a large range for suprathreshold activation up to the ceiling, explaining the lack of habituation after the repetition of the same stimuli. The reduced pre-activation explains also the reduced amplitude of early block that was found in visual [15, 22], auditory [23] and somatosensory [24] EPs but also in brainstem reflexes, where a reduced first reflex area under the curve was reported in migraineurs with respect to controls [18-20].

Results in favour of such hypothesis have been recently reported through sophisticated EP techniques analysing high-frequency oscillations (HFO) of somatosensory [25] and visual evoked potentials [26]. Indeed the authors find reduced amplitude of early component of HFO in SEP that is due to thalamo-cortical activation and reduced habituation of the late component of gamma band oscillations (GBO) in VEPs that is expression of visual cortical activation.

\section{Dysfunctions of cortical excitability in migraine: the contribution of non-invasive brain stimulation techniques}

Transcranial magnetic stimulation is a non-invasive and easy tool able to induce painless cerebral stimulation through application of a magnetic field on the scalp. Repeated magnetic pulses (repetitive TMS: rTMS) are able to induce long lasting plastic effects that last also after the end of the train and differ depending of the stimulation frequency employed: low frequencies $(\leq 1 \mathrm{~Hz})$ reduce while high frequencies $(>1 \mathrm{~Hz})$ increase cortical excitability. tDCS is transcranially administered through electrodes over the scalp and is thought to modulate cortical excitability by changing the potential of cell membranes due to anodal (facilitatory effect) or cathodal stimulation (inhibitory effect).

Due to these properties, rTMS and tDCS have been used to study cortical plasticity and to explore potential therapeutical application in several neuropsychiatric disorders [27].

In 1998 Aurora et al. using single-pulse TMS investigated the excitability of the visual cortex evaluating the stimulation intensity needed to induce the perception of phosphenes (phosphene threshold: PT). The authors found that lower magnetic stimulation intensity was needed to induce phosphenes in migraineurs compared to controls and concluded that the migraine brain is hyperexcitable [28]. Further evidence of increased excitability of primary visual cortex with the same technique was reported also by other studies [29-31]. In 2002, Batelli et al. reported also hyperexcitability of the extrastriate cortex V5 (an area particularly devoted to visual perception of motion) showing reduced threshold for the induction of "moving phosphenes", particular phosphenes that are perceived to move in the visual field [32].

Other studies, however, found different results reporting higher variability of PT values in migraineurs [33] and lower prevalence of phosphenes in migraineurs with 
respect to healthy controls $[34,35]$, pointing toward hyporather than hyper-excitability of visual cortex in migraine. According to this view, more recently, Lo et al. (2008) found lower prevalence of phosphenes in migraine patients showing a worse clinical picture [36].

\section{Studies of cortical modulation and evidence of reduced efficiency of inhibitory circuits in migraine}

The application of rTMS and tDCS allowed interesting advance in the issue of cortical excitability, giving the chance to better investigate responsiveness and modulatory properties of cortical areas in migraine (see Table 1). In 2002 Bohotin et al. [37] used rTMS to explore the effects on habituation to visual evoked potentials in migraine.

The authors found that hf-rTMS (that show facilitatory effects in normals) is able to restore habituation in migraineurs, while low-frequency (lf) rTMS disrupted habituation in healthy subjects. They explained these results, as a facilitating effect of rTMS in migraine and an inhibitory one in healthy subjects, thus supposing visual cortex in migraine to be hypo-active. This interpretation results facile in light of recent evidence about the role of basal cortical status in determining the rTMS modulation effect, which seemed paradoxical in condition of increased cortical excitability $[13,14]$. So we think that a risk of circular reasoning occurs using rTMS to ascertain cortical excitability in migraine as rTMS effect itself could be affected by the same phenomenon (cortical excitability) that rTMS should evaluate.

Indeed, using $1 \mathrm{~Hz}$ rTMS that shows inhibitory effects in healthy subjects we found a paradoxical facilitatory behaviour in striate and extrastriate visual cortices of patients affected by migraine with aura [38, 39]. Considering the effects of $1 \mathrm{~Hz}$ rTMS on the visual cortex of healthy subjects as following to LTD like mechanisms (see Boorojerdi et al. 2000 [40]) these findings evidence a dysfunctioning LTD mechanism in migraine. Interestingly, this put our results partly in agreement with those obtained by Bolla et al. (2007) [41] that also showed LTD impairment studying the effects of rTMS on VEPs.

Differently from Bolla et al. (2007) [41], we interpreted this dysfunction as consequent upon a reduced activity of inhibitory circuits unable to be up-regulated by low-frequency stimulation. This is because the inhibitory effects of lf-rTMS depend on the integrity of cortical inhibition and evidence in favour of reduced inhibition of visual cortex had been previously reported in TMS papers where the effects of GABA-ergic drugs were evaluated [42] and also in the majority of psychophysical studies [43] with the exception of the data by Shepherd et al. 2001, 2006 [44, 45]. Moreover, we also obtained more direct evidence of reduced efficiency of intracortical inhibitory circuits in a further study on motor cortex. Indeed, using the paired pulse TMS technique that allows selective assessment of intracortical inhibition (ICI), we found reduced ICI levels in baseline in migraine patients together with a paradoxical response of intracortical faciltatory circuits after $1 \mathrm{~Hz}$ rTMS, similar to that observed in visual cortex [46].

Other direct evidence of impaired inhibition came also by studies of silent period (SP), a measure of spinal and cortical inhibition that principally depends on activity of GABAB circuits. All but one [47] studies found a significant reduction of SP in migraine patients $[48,49]$. In particular, more specific evidence of the reduced cortical inhibition was recently provided by Currà et al. that found reduced SP in facial muscle (where SP depends entirely on cortical inhibition) [49]. More recently evidence in favour of a reduced activity of cortical inhibitory circuits has been reported also by technique of tDCS in patients affected by migraine with aura [50]. A question could be raised because the mentioned evidence concerns only cortical structures while LTD dysfunctions have been reported also for brainstem responses like blink reflex (BR) [17-20]. However, it has been shown that BR can be modulated by GABA neurotransmission [51] and that changes in BR reactivity could also be determined by cortical modulation (in a recent rTMS study stimulation of motor cortex was found able to modulate BR) [52]. Moreover, the descending modulatory influences of cortical areas on brainstem nuclei involved in pain control and their potential role in precipitating migraine attacks have been recently described $[53,54]$.

\section{Cortical inhibition and sensory deafferentation}

The picture of reduced inhibition and paradoxical facilitatory responses we observed in migraineurs presents interesting similarities with neurophysiological changes observed in conditions of deafferentation-induced-plasticity. Indeed, in experimental animals it was shown that deafferentation induces rapid plastic changes that are principally mediated by the unmasking of existent but latent cortico-cortical connections and that the mechanisms involved include removal of local inhibition [55-57]. Moreover, in a study of functional deafferentation of the sensory-motor cortex performed through transient ischaemia of the forearm in healthy subjects [58, 59], Ziemann et al. found down-regulation of inhibitory circuits and paradoxical responses to rTMS similar to that we found in migraine patients. Indeed, they found that the abnormalities of cortical excitability could be pharmacologically corrected by GABA active drugs [59], suggesting that the rapid removal of GABA-related inhibition is a necessary step for this form of deafferentation-induced plasticity. Previously we found similar neurophysiological abnormalities in 
Table 1 rTMS and tDCS studies in migraine and in controls (including functional deafferentation models: [60, 73])

\begin{tabular}{|c|c|c|c|c|c|}
\hline Authors & Subjects & Cortex & Methods & Outcome & Results \\
\hline Bohotin et al. [37] & $\begin{array}{l}\text { Controls } \\
\text { MO, MA }\end{array}$ & Striate & $\begin{array}{l}\text { 1, } 10 \mathrm{~Hz} \text { rTMS } \\
\text { VEPs habituation }\end{array}$ & $\begin{array}{l}\text { Effects of } 1 \mathrm{~Hz} \\
\text { and } 10 \mathrm{~Hz} \text { on } \\
\text { VEPs habituation }\end{array}$ & $\begin{array}{l}\text { Normalization of VEPs habituation } \\
\text { in migraine with } 10 \mathrm{~Hz} \text { rTMS } \\
\text { Impairment of VEPs habituation in } \\
\text { controls with } 1 \mathrm{~Hz} \text { rTMS }\end{array}$ \\
\hline Brighina et al. [38] & $\begin{array}{l}\text { Controls } \\
\text { MA }\end{array}$ & Striate & $\begin{array}{l}1 \mathrm{~Hz} \text { rTMS } \\
\text { PT }\end{array}$ & $\begin{array}{l}\text { Effects of } 1 \mathrm{~Hz} \text { rTMS on } \\
\text { PT }\end{array}$ & $\begin{array}{l}\uparrow \mathrm{PT} \text { in controls } \\
\downarrow \mathrm{PT} \text { in MA patients }\end{array}$ \\
\hline Fierro et al. [39] & $\begin{array}{l}\text { Controls } \\
\text { MA }\end{array}$ & Extra-striate & $\begin{array}{l}1 \mathrm{~Hz} \text { rTMS } \\
\text { Kaniza's figures }\end{array}$ & $\begin{array}{l}\text { Effects of } 1 \mathrm{~Hz} \text { rTMS on } \\
\text { RT to perceptual } \\
\text { contours perception }\end{array}$ & $\begin{array}{l}\uparrow \mathrm{RTs} \text { in controls } \\
\downarrow \mathrm{RTs} \text { in MA patients }\end{array}$ \\
\hline Brighina et al. [46] & $\begin{array}{l}\text { Controls } \\
\text { MA }\end{array}$ & Motor & $\begin{array}{l}\text { pp-TMS }(2,10 \mathrm{~ms} \\
\text { ISI }) \\
1 \mathrm{~Hz} \mathrm{rTMS}\end{array}$ & $\begin{array}{l}\text { SICI, ICF } \\
\text { Effects of } 1 \mathrm{~Hz} \text { rTMS on } \\
\quad \text { SICI and ICF }\end{array}$ & $\begin{array}{l}\downarrow \text { SICI in MA } \\
\downarrow \text { ICF in controls } \uparrow \text { ICF in MA after } \\
\quad 1 \mathrm{~Hz} \text { rTMS } \\
\text { No effects on SICI after } 1 \mathrm{~Hz} \text { rTMS }\end{array}$ \\
\hline Fierro et al. [60] & Controls & Striate & $\begin{array}{l}\text { Light deprivation } \\
\text { (LD) } \\
1,10 \mathrm{~Hz} \text { rTMS } \\
\text { PT }\end{array}$ & $\begin{array}{l}\text { Visual cortical excitability } \\
(\mathrm{PT}) \text { changes in LD with } \\
\text { and without rTMS }(1 \mathrm{~Hz} \\
\text { and } 10 \mathrm{~Hz}) \\
\text { PT recovery time after ligh } \\
\text { re-exposure (PTR) }\end{array}$ & $\begin{array}{l}\text { LD increases visual cortex } \\
\text { excitability } \\
\text { LD + } 1 \text { Hz rTMS: } \uparrow \text { PTR } \\
\text { LD + } 10 \text { Hz rTMS: } \downarrow \text { PTR }\end{array}$ \\
\hline Fumal et al. [74] & $\begin{array}{l}\text { Controls } \\
\text { MO, MA }\end{array}$ & Striate & $\begin{array}{l}\text { 1, } 10 \mathrm{~Hz} \text { rTMS ( } 5 \\
\text { days) } \\
\text { VEPs habituation }\end{array}$ & $\begin{array}{l}\text { Long-term effects of } 1 \mathrm{~Hz} \\
\text { and } 10 \mathrm{~Hz} \text { on VEPs } \\
\text { habituation }\end{array}$ & $\begin{array}{l}10 \mathrm{~Hz} \text { rTMS: long lasting } \\
\text { normalization of VEPs } \\
\text { habituation in MO, MA } \\
1 \mathrm{~Hz} \text { rTMS: long lasting } \\
\text { impairment of VEPs habituation } \\
\text { in controls }\end{array}$ \\
\hline Chadaide et al. [50] & $\begin{array}{l}\text { Controls } \\
\text { MO, MA }\end{array}$ & Striate & $\begin{array}{l}\text { Cathodal, anodal } \\
\text { tDCS PT }\end{array}$ & $\begin{array}{l}\text { Effects of cathodal, anodal } \\
\text { tDCS on PT }\end{array}$ & $\begin{array}{l}\text { Anodal tDCS } \downarrow \text { PT in MA more } \\
\text { than in controls } \\
\text { catodal tDCS } \uparrow \text { PT in controls, no } \\
\text { effect in MA, MO }\end{array}$ \\
\hline Bolla et al. [41] & $\begin{array}{l}\text { Controls } \\
\mathrm{MO}\end{array}$ & Striate & $\begin{array}{l}9 \text { Hz rTMS VEPs } \\
\text { habituation }\end{array}$ & LTP/LTD effects on VEPs & $\begin{array}{l}\text { LTD ( } \downarrow \text { VEPs amplitude) and } \\
\downarrow \text { VEPs habituation in controls } \\
\text { No effects in MO patients }\end{array}$ \\
\hline Antal et al. [71] & $\begin{array}{l}\text { Controls } \\
\text { MA }\end{array}$ & Motor & $\begin{array}{l}\text { Cathodal, anodal } \\
\text { tDCS } 5 \mathrm{~Hz} \\
\text { rTMS }\end{array}$ & $\begin{array}{l}\text { Homeostatic plasticity: } \\
\text { effects of tDCS on rTMS } \\
\text { modulation }\end{array}$ & $\begin{array}{l}\text { Anodal tDCS: no homeostatic } \\
\text { effects (no MEP changes) in MA } \\
\text { catodal tDCS: homeostatic effect in } \\
\text { MA and controls }\end{array}$ \\
\hline Palermo et al. [73] & Controls & Striate & $\begin{array}{l}\text { Light deprivation } \\
\text { (LD) } \\
1,10 \mathrm{~Hz} \text { rTMS } \\
\text { VEPs habituation }\end{array}$ & $\begin{array}{l}\text { Effects of LD with/without } \\
\text { rTMS on VEPs } \\
\text { habituation }\end{array}$ & $\begin{array}{l}\text { LD impairs VEPs habituation } \\
\text { LD }+1 \mathrm{~Hz} \text { impairs VEPs } \\
\text { habituation } \\
\text { LD }+10 \mathrm{~Hz} \text { restores VEPs } \\
\text { habituation }\end{array}$ \\
\hline
\end{tabular}

See text for details

$M A$ migraine with aura, $M O$ migraine without aura, VEPs visual evoked potentials, $r T M S$ repetitive transcranial magnetic stimulation, $P T$ phosphene threshold, $R T$ reaction time, $I S I$ inter-stimulus interval, SICI short lasting intracortical inhibition, ICF intracortical facilitation, LTP long-term potentiation, LTD long-term depression, $t D C S$ transcranial direct current stimulation

healthy subjects undergoing functional visual cortical deafferentation induced by short-term light deprivation [60]. In this condition visual cortex showed increased excitability and a paradoxical pattern of synaptic strengthening to rTMS. Lf-rTMS induced facilitatory effects while hf-rTMS showed an inhibitory effect restoring normal excitability levels.
The condition of deafferentation-induced-plasticity parallels in some way the theory of "reduced thalamocortical activity" that results in cortical hyper responsivity [11]. In this picture we think that deafferentation could act, at least in part, through reduced inhibition, because in models of deafferentation and short-term plasticity of visual cortex, down-regulation of GABA circuits has been 
shown to exert an important role [40, 61-63]. Facilitatory mechanisms seem to be prevalent in visual adaptation $[64,65]$; however, the interplay between excitation and inhibition has important functional role in mechanism of experience-dependent plasticity and deafferentation [66]. Moreover, as showed recently, integrity of GABA circuits is critical to maintain a normal state of homeostatic plasticity in visual cortex [67].

Aside from sensorial deafferentation, paradoxical effect of inhibitory changes by high-frequency rTMS have been also described in other conditions of altered cortical excitability like Parkinson's disease [68] or neuropathic pain [69]. In both conditions cortical inhibition was defective and could be restored by hf-rTMS trains.

Changes or dysfunctions in homeostatic plasticity have been invoked to explain paradoxical responses in condition of increased excitability following deafferentation or not. Impairment of homeostatic plasticity has been described in patient with dystonia [70] and very recently also in migraine [71]. Antal et al. (2008), studying the priming effects of tDCS on hf-rTMS train, found a reduced homeostatic-plasticity response in migraine, that differently from controls showed no inhibitory effect to hf-rTMS after the priming with excitatory anodal tDCS currents.

\section{Relationship between cortical inhibition and habituation and potential therapeutic approaches}

Impaired habituation has been consistently reported in migraine, extending to all sensory modalities, and is considered to represent a neurophysiological hallmark of the disease [8]. The neural mechanisms underlying this phenomenon, however, remain still to be cleared. According to the hypothesis by Schoenen et al., a reduced level of cortical pre-activation, probably following impairment of serotoninergic transmission, could account for the lack of habituation [8, 21]. In their recent review the authors [8] indeed consider that the reduced HFO, evidenced in somatosensory potential (reflecting a reduced thalamocortical activation), could underlie the basal hypo-activity of the sensory cortices. In our opinion the reduced efficiency of inhibitory circuits could represent a valid background to impaired habituation, in migraine as a consistent bulk of evidence supports the reduced activity of inhibitory circuits in migraine $[13,14,29,30,38,39,42$, $43,46,48-50]$. This could apply not only for cortical but also for sub-cortical structures (see lack of habituation of BR) where it could occur through local GABA dysfunction (see Harsing 2006 about the interplay between GABA and 5HT neurons at brainstem level [72]) or following abnormal cortical modulation [53, 54].
Then, could reduced inhibition play a pathophysiological role disrupting habituation in migraine? We recently explored this hypothesis studying the changes in VEPs habituation in a model of functional visual deafferentation induced by light deprivation [60] (a condition in which a change in visual cortical excitability occurs, likely due to down-regulation of inhibitory circuits) in healthy subjects (paper presented at 12th Congress of the European Federation of Neurological Societies [73]). In this experimental set we evaluated also the effects of low- and high-frequency magnetic stimulation. We found impaired habituation to VEPs in normal subjects, after 60 min of visual deprivation. Moreover, hf-rTMS, which probably acts through up-regulation of inhibitory circuits, was able to completely restore habituation. As visual deafferentation very likely determines down-regulation of GABA circuits, these results support the existence of a causal link between reduced inhibition and impaired habituation.

The restoring effects of hf-rTMS deserve particular interest also under the respect of potential therapeutic applications. Under this respect our results are in agreement with those by Bohotin et al. (2002) [37] that showed the ability of hf-rTMS to restore VEPs habituation in migraineurs, and with a further study by the same group [74] showing that repeated trains of $10 \mathrm{~Hz}$ rTMS were able to normalize habituation to VEPS with plastic effects lasting over time. This, even if authors propose different explanation, hypothesizing that hf-rTMS would act through a facilitatory effect, able to correct the condition of reduced cortical pre-activation.

We also showed lasting beneficial effects by hf-rTMS of the left dorsolateral prefrontal cortex in a group of patients affected by chronic migraine [75].

Therefore these studies, even if based on different pathophysiological views, reach similar conclusions, opening new, attractive prospects for the potential therapeutical application of hf-rTMS in migraine.

\section{Conclusions and final remarks}

Impaired habituation probably represents a neurophysiological marker of migraine [8, 11, 21]. A consistent bulk of evidence highlights also the role of reduced cortical inhibition in the pathophysiology of this disease [13, 14, 29, $30,38,39,42,43,46,48-50]$. Reduced pre-activation of sensory cortices, likely following to thalamo-cortical dysfunctions $[8,11,21]$, has been proposed as the principal pathogenetic mechanism for impaired habituation. According to this view a reduced thalamo-cortical activation would also explain reduced efficiency of cortical inhibitory circuits through the impairment of collateral 
inhibition [8]. However, following to reduced thalamic drive also facilitatory circuits should be impaired, but this does not seem the case, as on the contrary, hyperexcitability of facilitatory circuits has been reported [76]. Anyway, thalamic abnormal activation (suggested on the basis of reduced HFO) would also explain the reduced amplitude of the first train of VEPs through an initial defect in synchronization of evoked responses without the need to invoke a condition of reduced cortical pre-activation. Indeed, thalamic processing plays an important role in synchronization of sensory inputs. More, thalamic function is also controlled by modulatory cortical influences that play a fundamental role in synchronizing the activities of thalamic and cortical neurons needed for adequate timing of brain activities [77]. Therefore, changes in cortical activity could also determine changes in HFO components of SEPs as it has been showed in recent studies exploring the effects of brain stimulation on HFO component [78, 79]. In one of these studies in particular, the authors found similar effects of theta burst rTMS on HFO and on cortical inhibition [79].

We think that reduced cortical inhibition could play a role in pathophysiology of migraine, included impaired habituation, even if this does not directly mean that the cortex is the primitive cause. Indeed, in our model of functional visual deafferentation (that acts through down-regulation of inhibitory circuits), habituation becomes impaired and subjects present paradoxical responses to low-frequency stimulation as that found in migraine. In our opinion the analogies between migraine and experimental models of sensory deafferentation are particularly interesting, considering that the neurophysiological findings of reduced inhibition and paradoxical facilitation were common to both states. Disruption of habituation has been described in diseased state, like tinnitus [80] where deafferentation of acoustic cortex is believed to be the principal pathogenetic mechanism. On the other hand, receptorial dysfunction in visual [81], olfactory [82] and more recently in auditory [83] and vestibular systems [84, 85] have been described in migraine. Could they play any role in generation of functional cortical abnormalities observed in this disease, through mechanisms like those operating in deafferentation? It is known that disruption of receptor function cannot directly affect habituation that depends on central cortical and subcortical structures and is not related to changes in receptor adaptation. However, receptor dysfunction can induce relevant cortical reorganization that could dramatically affect cortical responsivity. Indeed, in patients with achromatopsia (a disease affecting cone receptors and colour vision) Baseler et al. (2002) [86], in a fMRI study showed a large scale developmental reorganization of visual cortex with a markedly increased responsivity to light. In the same way, acoustic deafferentation that has been shown at the basis of tinnitus, gives raise to a reorganization of acoustic cortex that induces a particular sensitivity to sounds [87]. Moreover in these patients, decreasing cortical excitability through low-frequency rTMS was found to be able to relieve tinnitus [88]. Concerning the mechanisms involved in such reorganization, it is interesting to note that downregulation of inhibition has been described in a manner similar to what occurs in other deafferentation conditions [89, 90]. On the other hand deafferentation and activity dependent plasticity can induce changes of cortical as well as subcortical structures like thalamus and brainstem [91]. Therefore, in our opinion, it is probable that central cortical and subcortical plastic changes induced by receptor dysfunction could contribute (together with other factor) to affect excitability and responsivity of CNS in migraine, predisposing to migraine attacks. This is to be considered of course only as a working hypothesis that is worth to be explored to better understand neural mechanisms underlying pathophysiology, opening also new treatment strategies for migraine.

\section{Conflict of interest None.}

\section{References}

1. Pietrobon D (2005) Migraine: new molecular mechanisms. Neuroscientist 11:373-386

2. Olesen J, Larsen B, Lauritzen M (1981) Focal hyperemia followed by spreading oligemia and impaired activation of $\mathrm{rCBF}$ in classic migraine. Ann Neurol 9:344-352

3. Hadjikhani N, Sanchez Del Rio M, Wu O et al (2001) Mechanisms of migraine aura revealed by functional MRI in human visual cortex. Proc Natl Acad Sci USA 98:4687-4692

4. Pietrobon D (2007) Familial hemiplegic migraine. Neurotherapeutics 4:274-284

5. Bolay H, Reuter U, Dunn AK et al (2002) Intrinsic brain activity triggers trigeminal meningeal afferents in a migraine model. Nat Med 8:136-142

6. Schoenen J, Ambrosini A, Sándor PS, Maertens de Noordhout A (2003) Evoked potentials and transcranial magnetic stimulation in migraine: published data and viewpoint on their pathophysiologic significance. Clin Neurophysiol 114:955-972

7. Schoenen J (2006) Neurophysiological features of the migrainous brain. Neurol Sci 27(suppl 2):S77-S81

8. Coppola G, Pierelli F, Schoenen J (2008) Habituation and migraine. Neurobiol Learn Mem [Epub ahead of print]

9. Stankewitz A, May A (2007) Cortical excitability and migraine. Cephalalgia 27:1454-1456

10. Sandor PS (2007) Migraine excitability. Cephalalgia 27(12):1440-1441

11. Coppola G, Pierelli F, Schoenen J (2007) Is the cerebral cortex hyperexcitable or hyperresponsive in migraine? Cephalalgia 27:1427-1439

12. Aurora SK, Barrodale P, Chronicle EP, Mulleners WM (2005) Cortical inhibition is reduced in chronic and episodic migraine and demonstrates a spectrum of illness. Headache 45:546-552

13. Brighina F, Fierro B (2007) Cortical hypoactivity or reduced efficiency of cortical inhibition in migraine? Cephalalgia 27:187188 (author reply 188-189) 
14. Valeriani M, Fierro B, Brighina F (2007) Brain excitability in migraine: hyperexcitability or inhibited inhibition? Pain 132:219220

15. Schoenen J, Wang W, Albert A, Delwaide PJ (1995) Potentiation instead of habituation characterizes visual evoked potentials in migraine patients between attacks. Eur J Neurol 2:115-122

16. de Tommaso M (2008) Laser-evoked potentials in primary headaches and cranial neuralgias. Expert Rev Neurother 8:13391345

17. De Marinis M, Pujia A, Natale L, D'arcangelo E, Accornero $\mathrm{N}$ (2003) Decreased habituation of the R2 component of the blink reflex in migraine patients. Clin Neurophysiol 114:889-893

18. Katsarava Z, Giffin N, Diener H, Kaube H (2003) Abnormal habituation of 'nociceptive' blink reflex in migraine-evidence for increased excitability of trigeminal nociception. Cephalalgia 23:814-819

19. Di Clemente L, Coppola G, Magis D, Fumal A, De Pasqua V, Schoenen J (2005) Nociceptive blink reflex and visual evoked potential habituations are correlated in migraine. Headache 45:1388-1393

20. Di Clemente L, Coppola G, Magis D, Fumal A, De Pasqua V, Di Piero V, Schoenen J (2007) Interictal habituation deficit of the nociceptive blink reflex: an endophenotypic marker for presymptomatic migraine? Brain 130:765-770

21. Schoenen J (1996) Deficient habituation of evoked cortical potentials in migraine: a link between brain biology, behavior and trigeminovascular activation? Biomed Pharmacother 50:71-78

22. Afra J, Proietti Cecchini A, De Pasqua V, Albert A, Schoenen J (1998) Visual evoked potentials during long periods of patternreversal stimulation in migraine. Brain 121:233-241

23. Ambrosini A, Rossi P, De Pasqua V, Pierelli F, Schoenen J (2003) Lack of habituation causes high intensity dependence of auditory evoked cortical potentials in migraine. Brain $126(\mathrm{Pt}$ 9):2009-2015

24. Ozkul Y, Uckardes A (2002) Median nerve somatosensory evoked potentials in migraine. Eur J Neurol 9:227-232

25. Coppola G, Vandenheede M, Di Clemente L, Ambrosini A, Fumal A, De Pasqua V et al (2005) Somatosensory evoked high-frequency oscillations reflecting thalamo-cortical activity are decreased in migraine patients between attacks. Brain 128:98-103

26. Coppola G, Ambrosini A, Di Clemente L, Magis D, Fumal A, Gérard P et al (2007) Interictal abnormalities of gamma band activity in visual evoked responses in migraine: an indication of thalamocortical dysrhythmia? Cephalalgia 27:1323-1330

27. Fregni F, Pascual-Leone A (2007) Technology insight: noninvasive brain stimulation in neurology-perspectives on the therapeutic potential of rTMS and tDCS. Nat Clin Pract Neurol 3:383-393

28. Aurora SK, Ahmad BK, Welch KM, Bhardhwaj P, Ramadan NM (1998) Transcranial magnetic stimulation confirms hyperexcitability of occipital cortex in migraine. Neurology 50:1111-1114

29. Mulleners WM, Chronicle EP, Palmer JE, Koehler PJ, Vredeveld JW (2001) Visual cortex excitability in migraine with and without aura. Headache 41:565-572

30. Mulleners WM, Chronicle EP, Palmer JE, Koehler PJ, Vredeveld JW (2001) Suppression of perception in migraine: evidence for reduced inhibition in the visual cortex. Neurology 56:178-183

31. Aurora SK, Chronicle EP (2002) Migraine's magnetic attraction. Lancet Neurol 1:211

32. Battelli L, Black KR, Wray SH (2002) Transcranial magnetic stimulation of visual areaV5 in migraine. Neurology 58:1066-1069

33. Antal A, Arlt S, Nitsche MA, Chadaide Z, Paulus W (2006) Higher variability of phosphene thresholds in migraineurs than in controls: a consecutive transcranial magnetic stimulation study. Cephalalgia 26:865-870
34. Afra J, Mascia A, Gerard P, Maertens de Noordhout A, Schoenen J (1998) Interictal cortical excitability in migraine: a study using transcranial magnetic stimulation of motor and visual cortices. Ann Neurol 44:209-215

35. Bohotin V, Fumal A, Vandenheede M, Bohotin C, Schoenen J (2003) Excitability of visual V1-V2 and motor cortices to single transcranial magnetic stimuli in migraine: a reappraisal using a figure-of-eight coil. Cephalalgia 23:264-270

36. Lo YL, Lum SY, Fook-Chong S, Cui SL, Siow HC (2008) Clinical correlates of phosphene perception in migraine without aura: an Asian study. J Neurol Sci 15(264):93-96

37. Bohotin V, Fumal A, Vandenheede M, Gerard P, Bohotin C, Maertens de Noordhout A, Schoenen J (2002) Effects of repetitive transcranial magnetic stimulation on visual evoked potentials in migraine. Brain 125:912-922

38. Brighina F, Piazza A, Daniele O, Fierro B (2002) Modulation of visual cortical excitability in migraine with aura: effects of $1 \mathrm{~Hz}$ repetitive transcranial magnetic stimulation. Exp Brain Res 145:177-181

39. Fierro B, Ricci R, Piazza A, Scalia S, Giglia G, Vitello G, Brighina F (2003) $1 \mathrm{~Hz}$ rTMS enhances extrastriate cortex activity in migraine: evidence of a reduced inhibition? Neurology 61:1446-1448

40. Boroojerdi B, Bushara KO, Corwell B, Immisch I, Battaglia F, Muellbacher W, Cohen LG (2000) Enhanced excitability of the human visual cortex induced by short-term light deprivation. Cereb Cortex 10:529-534

41. Bolla M, Coppola G, De Pasqua V, Gerardy PY, Kazadi EK, Magis D, Schoenen J (2007) Conditioning by high frequency visual stimuli of the visual evoked potential in healthy volunteers and migraineurs. Cephalalgia 27:715

42. Mulleners WM, Chronicle EP, Vredeveld JW, Koehler PJ (2002) Visual cortex excitability in migraine before and after valproate prophylaxis: a pilot study using TMS. Eur J Neurol 9(1):35-40

43. Palmer JE, Chronicle EP, Rolan P, Mulleners WM (2000) Cortical hyperexcitability is cortical under-inhibition: evidence from a novel functional test of migraine patients. Cephalalgia 20:525532

44. Shepherd AJ (2001) Increased visual after-effects following pattern adaptation in migraine: a lack of intracortical excitation? Brain 124:2310-2318

45. Shepherd AJ (2006) Local and global motion after-effects are both enhanced in migraine, and the underlying mechanisms differ across cortical areas. Brain 129:1833-1843

46. Brighina F, Giglia G, Scalia S, Francolini M, Palermo A, Fierro B (2005) Facilitatory effects of $1 \mathrm{~Hz}$ rTMS in motor cortex of patients affected by migraine with aura. Exp Brain Res $161: 34-38$

47. Werhahn KJ, Wiseman K, Herzog J, Förderreuther S, Dichgans M, Straube A (2000) Motor cortex excitability in patients with migraine with aura and hemiplegic migraine. Cephalalgia 20:45-50

48. Aurora SK, al-Sayeed F, Welch KM (1999) The cortical silent period is shortened in migraine with aura. Cephalalgia 19:708712

49. Curra A, Pierelli F, Coppola G, Barbanti P, Buzzi MG, Galeotti F, Serrao M, Truini A, Casal C, Pauri F, Cruccu G (2007) Shortened cortical silent period in facial muscles of patients with migraine. Pain 132:124-131

50. Chadaide Z, Arlt S, Antal A, Nitsche MA, Lang N, Paulus W (2007) Transcranial direct current stimulation reveals inhibitory deficiency in migraine. Cephalalgia 27:833-839

51. Chen FP, Evinger C (2006) Cerebellar modulation of trigeminal reflex blinks: interpositus neurons. J Neurosci 26:10569-10576

52. De Vito A, Gastaldo E, Tugnoli V, Eleopra R, Casula A, Tola MR, Granieri E, Quatrale R (2009) Effect of slow rTMS of motor 
cortex on the excitability of the blink reflex: a study in healthy humans. Clin Neurophysiol 120:174-180

53. Lambert GA, Zagami AS (2008) The mode of action of migraine triggers: a hypothesis. Headache [Epub ahead of print]

54. Lambert GA, Hoskin KL, Zagami AS (2008) Cortico-NRM influences on trigeminal neuronal sensation. Cephalalgia 28:640-652

55. Sanes JN, Donoghue JP (1997) Static and dynamic organization of motor cortex. Adv Neurol 73:277-296

56. Jacobs KM, Donoghue JP (1991) Reshaping the cortical motor map by unmasking latent intracortical connections. Science 251:944-947

57. Kirkwood A, Bear MF (1994) Hebbian synapses in visual cortex. J Neurosci 14:1634-1645

58. Ziemann U, Corwell B, Cohen LG (1998) Modulation of plasticity in human motor cortex after forearm ischemic nerve block. J Neurosci 18:1115-1123

59. Ziemann U, Hallett M, Cohen LG (1998) Mechanisms of deafferentation-induced plasticity in human motor cortex. J Neurosci 18:7000-7007

60. Fierro B, Brighina F, Vitello G, Piazza A, Scalia S, Giglia G, Daniele O, Pascual-Leone A (2005) Modulatory effects of lowand high-frequency repetitive transcranial magnetic stimulation on visual cortex of healthy subjects undergoing light deprivation. J Physiol 565(2):659-665

61. Hendry SH, Fuchs J, deBlas AL, Jones EG (1990) Distribution and plasticity of immunocytochemically localized GABAA receptors in adult monkey visual cortex. J Neurosci 10:24382450

62. Jones EG (1993) GABAergic neurons and their role in cortical plasticity in primates. Cereb Cortex 3:361-372

63. Rosier AM, Arckens L, Demeulemeester H, Orban GA, Eysel UT, Wu YJ, Vandesande F (1995) Effect of sensory deafferentation on immunoreactivity of GABAergic cells and on GABA receptors in the adult cat visual cortex. J Comp Neurol 359:476489

64. Vidyasagar TR (1990) Pattern adaptation in cat visual cortex is a co-operative phenomenon. Neuroscience 36:175-179

65. McLean J, Palmer LA (1996) Contrast adaptation and excitatory amino acid receptors in cat striate cortex. Visual Neurosci 13:1069-1087

66. Gilbert CD (1998) Adult Cortical Dynamics Physiol. Rev 78:467-485

67. Le Roux N, Amar M, Moreau A, Baux G, Fossier P (2008) Impaired GABAergic transmission disrupts normal homeostatic plasticity in rat cortical networks. Eur J Neurosci 27:3244-3256

68. Fierro B, Brighina F, D'Amelio M, Daniele O, Lupo I, Ragonese P, Palermo A, Savettieri G (2008) Motor intracortical inhibition in PD: L-DOPA modulation of high-frequency rTMS effects. Exp Brain Res 184:521-528

69. Lefaucheur JP, Drouot X, Ménard-Lefaucheur I, Keravel Y, Nguyen JP (2006) Motor cortex rTMS restores defective intracortical inhibition in chronic neuropathic pain. Neurology 67:1568-1574

70. Quartarone A, Rizzo V, Bagnato S, Morgante F, Sant'Angelo A, Romano M, Crupi D, Girlanda P, Rothwell JC, Siebner HR (2005) Homeostatic-like plasticity of the primary motor hand area is impaired in focal hand dystonia. Brain 128:19431950

71. Antal A, Lang N, Boros K, Nitsche M, Siebner HR, Paulus W (2008) Homeostatic metaplasticity of the motor cortex is altered during headache-free intervals in migraine with Aura. Cereb Cortex 18:2701-2705

72. Harsing LG (2006) The pharmacology of the neurochemical transmission in the midbrain raphe nuclei of the rat. Curr Neuropharmacol 4:313-339
73. Palermo A, Brighina F, Giglia G, Puma AR, Panetta ML, Fierro B (2008) Cortical inhibition affects habituation to visual evoked potentials combined effects of light deprivation and repetitive transcranial magnetic stimulation in healthy subjects. Europ J Neurol 15(suppl 3):410

74. Fumal A, Coppola G, Bohotin V, Gerardy PY, Seidel L, Donneau AF, Vandenheede M, Maertens de Noordhout A, Schonen J (2006) Induction of long-lasting changes of visual cortex excitability by five daily sessions of repetitive transcranial magnetic stimulation (rTMS) in healthy volunteers and migraine patients. Cephalalgia 26:143-149

75. Brighina F, Piazza A, Vitello G, Aloisio A, Palermo A, Daniele O, Fierro B (2004) rTMS of the prefrontal cortex in the treatment of chronic migraine: a pilot study. J Neurol Sci 15(227):67-71

76. Siniatchkin M, Kröner-Herwig B, Kocabiyik E, Rothenberger A (2007) Intracortical inhibition and facilitation in migraine-a transcranial magnetic stimulation study. Headache 47:364-370

77. Jones EG (2002) Thalamic circuitry and thalamocortical synchrony. Philos Trans R Soc Lond B 357:1659-1673

78. Murakami T, Sakuma K, Nomura T, Uemura Y, Hashimoto I, Nakashima K (2008) Changes in somatosensory-evoked potentials and high-frequency oscillations after paired-associative stimulation. Exp Brain Res 184:339-347

79. Murakami T, Sakuma K, Nomura T, Nakashima K, Hashimoto I (2008) High-frequency oscillations change in parallel with shortinterval intracortical inhibition after theta burst magnetic stimulation. Clin Neurophysiol 119:301-308

80. Walpurger V, Hebing-Lennartz G, Denecke H, Pietrowsky R (2003) Habituation deficit in auditory event-related potentials in tinnitus complainers. Hear Res 181(1-2):57-64

81. Shepherd AJ (2004) Colour vision in migraine: selective deficits for S-cone discriminations. Cephalalgia 25:412-423

82. Grosser K, Oelkers R, Hummel T, Geisslinger G, Brune K, Kobal G, Lötsch J (2000) Olfactory and trigeminal event-related potentials in migraine. Cephalalgia 20:621-631

83. Bolay H, Bayazit YA, Gündüz B, Ugur AK, Akçali D, Altunyay S, Ilica S, Babacan A (2008) Subclinical dysfunction of cochlea and cochlear efferents in migraine: an otoacoustic emission study. Cephalalgia 28:309-317

84. Allena M, Magis D, De Pasqua V, Schoenen J, Bisdorff AR (2007) The vestibulo-collic reflex is abnormal in migraine. Cephalalgia 27:1150-1155

85. Roceanu A, Allena M, De Pasqua V, Bisdorff A, Schoenen J (2008) Abnormalities of the vestibulo-collic reflex are similar in migraineurs with and without vertigo. Cephalalgia 28:988-990

86. Baseler HA, Brewer AA, Sharpe LT, Morland AB, Jägle H, Wandell BA (2002) Reorganization of human cortical maps caused by inherited photoreceptor abnormalities. Nat Neurosci 5:364-370

87. Eggermont JJ (2006) Cortical tonotopic map reorganization and its implications for treatment of tinnitus. Acta Otolaryngol Suppl (556): $9-12$

88. De Ridder D, De Mulder G, Verstraeten E, Seidman M, Elisevich K, Sunaert S, Kovacs S, Van der Kelen K, Van de Heyning P, Moller A (2007) Auditory cortex stimulation for tinnitus. Acta Neurochir Suppl 97:451-462

89. Brozoski TJ, Spires TJ, Bauer CA (2007) Vigabatrin, a GABA transaminase inhibitor, reversibly eliminates tinnitus in an animal model. J Assoc Res Otolaryngol 8:105-118

90. Alkhatib A, Biebel UW, Smolders JW (2006) Reduction of inhibition in the inferior colliculus after inner hair cell loss. Neuroreport 17:1493-1497

91. Jones EG (2000) Cortical and subcortical contributions to activity-dependent plasticity in primate somatosensory cortex. Annu Rev Neurosci 23:1-37 